\title{
Duration of empirical therapy in neonatal bacterial meningitis with third generation cephalosporin: a multicenter retrospective study
}

\author{
Zhi Zhao ${ }^{1,2}$, Xueying Hua ${ }^{2,3}$, Jialin Yư ${ }^{4}$, Haibo Zhang ${ }^{5}$, Juhua $\mathrm{Li}^{6}$, Zhankui Li ${ }^{7}$
}

\author{
${ }^{1}$ Department of Neonatology, Shanxi Province People's Hospital, Xi'an, Shanxi \\ Province, China \\ ${ }^{2}$ Department of Neonatology, Children's Hospital of Chongqing Medical University, \\ Ministry of Education Key Laboratory of Child Development and Disorders, \\ Chongqing, China \\ ${ }^{3}$ Key Laboratory of Pediatrics, International Science and Technology Cooperation Base \\ of Child Development and Critical Disorders, Chongqing, China \\ ${ }^{4}$ Department of Pediatrics, Shenzhen University General Hospital, Shenzhen, China \\ ${ }^{5}$ Department of Neonatology, Children's Hospital of Xi'an, Xi'an, Shanxi Province, China \\ ${ }^{6}$ Department of Neonatology, Children's Hospital of Xianyang, Xianyang, Shanxi \\ Province, China \\ ${ }^{7}$ Department of Neonatology, Northwest Women and Children's Hospital, Xi'an, \\ Shanxi Province, China
}

Submitted: 9 May 2017

Accepted: 8 August 2017

Arch Med Sci 2019; 15 (6): 1482-1489

DOI: https://doi.org/10.5114/aoms.2018.76938

Copyright (c) 2018 Termedia \& Banach

\begin{abstract}
Introduction: The duration of treatment is not well established, especially in the negative cerebrospinal fluid (CSF) culture. The aim of this study is to explore the influence of duration of treatment in neonatal bacterial meningitis. Material and methods: This is a retrospective analysis of 200 CSF specimens. Two hundred full-term neonates with bacterial meningitis admitted to the clinical status were evaluated using the Glasgow Outcome Scale (GOS) on the day of discharge.

Results: Neonates were identified as having bacterial meningitis based on the results of CSF culture tests of all suspected cases. According to the GOS, neonates were divided into two outcome groups: $77.5 \%$ good $(G O S=5)$ (shorter than 3 weeks' administration) and $22.5 \%$ unfavorable (GOS = 1-4) (longer than 3 weeks' administration). The duration of antibiotic treatment ranged from 4 to 43 days, and the mean therapy time was $19.74 \pm 7.32$ days. Duration longer than 3 weeks for neonatal bacterial meningitis with negative CSF culture had no impact on prognosis. The unfavorable outcome group had more prenatal infections and premature rupture of membranes cases than the good outcome group. High CSF protein and CSF glucose and CSF cell count increase were associated with unfavorable outcome in 167 non-prenatal infection infants. High CSF cell count increase was associated with unfavorable outcome in 33 prenatal infection infants. In term infants, the positive rate of blood cultures was $24.5 \%$. Conclusions: Third generation cephalosporin therapy does not have a different prognosis for negative CSF culture of neonatal bacterial meningitis in term infants in this study.
\end{abstract}

Key words: multicenter, bacterial meningitis, term infant, retrospective study.

\author{
Corresponding author: \\ Jialin Yu \\ Department of Pediatrics \\ Shenzhen University \\ General Hospital \\ 1098 XueYuan Avenue \\ Nanshan District \\ 518055 Shenzhen \\ Guangdong Province, China \\ E-mail: just8yue@sina.com
}




\section{Introduction}

Bacterial meningitis occurs more commonly in the first month of life than any other period, and frequently in infants associates with early onset sepsis (EOS) and late onset sepsis (LOS). The mortality from meningitis is close to $100 \%$ in untreated individuals and is still up to $40 \%$ in children who receive appropriate antibiotic treatment in developing countries [1-3]. Although in the United Kingdom the case fatality associated with neonatal meningitis declined from $25 \%$ to $10 \%$ between the 1980s and 1990s, long-term sequelae rates did not change, with up to $50 \%$ of survivors having long-term neurodevelopmental complications [4-6]. Early identification and prompt antibiotic treatment are essential for reducing mortality and morbidity. Decisions on the choice of a specific antimicrobial agent are based on knowledge of its activity against the causative pathogen and relative penetration into cerebrospinal fluid (CSF) in the presence of meningeal inflammation. In 2004, the Infectious Disease Society of America published practice guidelines for treatment of meningitis. A 14-day course is sufficient for neonates with uncomplicated group B streptococcus (GBS) meningitis and for other Gram-positive organisms, while a 21-day course of therapy is required for neonates with complicated GBS meningitis and Gram-negative microorganisms. If abscesses, multiple areas of infarction, or ventriculitis occur, it is suggested to administer antibiotics for 6-8 weeks [7-10]. However, in this practice's guidelines the duration of antimicrobial therapy has often been based more on tradition than on evidence-based data. Isolation of a pathogen in culture is a prerequisite for proven bacterial meningitis. Culture results take at least 48-72 h to be reported. In addition, its positivity rate is low, especially in the CSF, and is affected by sample volume inoculated, prenatal antibiotic use, level of bacteremia and laboratory capabilities. The early and appropriate initiation of antimicrobial agents in high risk neonates before the result of blood and (or) CSF culture susceptibility is defined as "empirical antibiotic therapy". With the worldwide increase in the prevalence of penicillin-resistance pneumococci, combination therapy with a third-generation cephalosporin (ceftriaxone sodium used in this study) plus vancomycin has become the standard approach to empirical antimicrobial therapy. The purpose of this study was to evaluate the effect of ceftriaxone treatment. Ceftriaxone sodium was used with penicillin partially plus vancomycin at the beginning of the treatment, which was immediately stopped if the clinical manifestations or test results improved (generally in 3-5 days). Hence, the cases included in this study were treated with ceftriaxone sodium only in the maximum period for treatment.
Third generation cephalosporin given to neonates with bacterial meningitis can rapid sterilize the cerebrospinal fluid in almost all patients [1113 ] and it is the recommended treatment in many countries $[14,15]$. For neonatal bacterial meningitis with negative CSF culture, the duration of antibiotic treatment is long and often associated with neurological sequelae, even though bacteria are no longer present and the baby is asymptomatic, because the treating physician fears stopping prematurely [16]. This prolonged and unnecessary use of antimicrobial treatment is associated with unnecessary costs and potential side-effects in neonates. Currently the duration of treatment in neonatal bacterial meningitis with negative CSF culture is based more on clinical experience than solid evidence [15-19]. In this study, we discuss the duration of treatment for clinical prognosis of neonatal bacterial meningitis.

\section{Material and methods}

\section{Data collection}

This study was approved by the Institutional Review Board of the Children's Hospital of Chongqing Medical University (Approval No.03/2016) and the Chinese Ethics Committee of Registering Clinical Trials (Approval No. ChiCTR-EOC-16008048). Medical records were collected for full-term (gestation age $\geq 37$ weeks) neonates with neonatal bacterial meningitis. Symptoms or clinical findings were categorized as not present if they were not mentioned in the medical records. From January 2010 to December 2014, we enrolled 282 full-term neonates (31 infants with cyanotic congenital heart disease, 16 infants with positive CSF culture, and 35 were also excluded from the analysis as no clinical data were available due to transfer to other centers) referred to us from 5 different neonatology departments in Chongqing and Shanxi Province, China. Including 110 cases collected from the Children's Hospital of Chongqing Medical University, 12 cases were collected from Shanxi Province People's Hospital, 110 cases were from the Children's Hospital of Xi'an, 40 cases were from the Children's Hospital of Xianyang and 10 cases were from the Northwest Women and Children's Hospital. Table I lists the exclusion criteria for the study and diagnostic criteria for bacterial meningitis. Meningitis occurring in the first $72 \mathrm{~h}$ of life was defined as early-onset meningitis (EOM) and that occurring beyond $72 \mathrm{~h}$ was defined as late-onset meningitis (LOM) [20-22].

Outcome data were scored according to the Glasgow Outcome Scale (GOS) at discharge. The clinical status was evaluated with the GOS as follows: 1 - death, 2 - persistent vegetative state, 3 - severe disability, 4 - moderate disability, 
Table I. Study criteria for enrolment and diagnosis

\begin{tabular}{|c|}
\hline Exclusion criteria at enrolment \\
\hline Gestation age $<37$ weeks \\
\hline $\begin{array}{l}\text { Pre-existing seizure disorders, cerebral palsy, } \\
\text { degenerative neurological disorders }\end{array}$ \\
\hline Known immunodeficiency states \\
\hline Active viral infections \\
\hline Known hypersensitivity to cephalosporins \\
\hline Cyanotic congenital heart disease \\
\hline Positive CSF culture \\
\hline Diagnostic criteria for bacterial meningitis \\
\hline Clinical variables: \\
\hline Temperature instability \\
\hline Heart rate $\geq 180$ beats $/ \mathrm{min}$ or $\leq 100$ beats $/ \mathrm{min}$ \\
\hline $\begin{array}{l}\text { Respiratory rate }>60 \text { breaths/min plus grunting or } \\
\text { desaturations }\end{array}$ \\
\hline Lethargy/altered mental status \\
\hline Glucose intolerance (plasma glucose > $10 \mathrm{mmol} / \mathrm{l}$ ) \\
\hline Feed intolerance \\
\hline Positive CSF Gram stain \\
\hline Inflammatory variables: \\
\hline $\begin{array}{l}\text { Leukocytosis (WBC count }>34 \times 10^{9} / \text { l) or } \\
\text { leukopenia (WBC count }<5 \times 10^{9} / \text { I) }\end{array}$ \\
\hline CSF absolute neutrophil count $1000 / \mu l$ or above \\
\hline Thrombocytopenia < $100 \times 10^{9} / 1$ \\
\hline CRP $>10 \mathrm{mg} / \mathrm{l}$ or $2 \mathrm{SD}$ above normal value \\
\hline $\begin{array}{l}\text { Procalcitonin }>8.1 \mathrm{mg} / \mathrm{dl} \text { or } 2 \mathrm{SD} \text { above normal } \\
\text { value }\end{array}$ \\
\hline WBC counts in CSF exceeding $21 \times 10^{6} / 1$ \\
\hline CSF protein concentration $>1500 \mathrm{mg} / \mathrm{l}$ \\
\hline $\begin{array}{l}\text { CSF glucose concentration }<30 \mathrm{mg} / \mathrm{dl} \text { or less than } \\
50 \% \text { of blood glucose }\end{array}$ \\
\hline
\end{tabular}

CSF - cerebrospinal fluid, WBC - white blood cells, CRP - C-reactive protein.

5 - good recovery or only minor sequelae [23]. Moderate or severe disability was defined as any of the following conditions: spasticity or muscle weakness in one or more limbs, hydrocephalus, seizures disorder and hearing loss. According to the criteria of GOS, patients were classified into two prognosis groups: good ( 155 cases, $77.5 \%$. GOS $=5$ ) or adverse ( 45 cases, $22.5 \%$. GOS $=1-4$ ). Five was considered favorable and 1-4 as unfavorable.

\section{Statistical analysis}

All statistical analyses were performed using SAS9.4. Clinical characteristics of the two groups were described by mean values and standard deviations (median and interquartile ranges were used for non-normally distributed variables) or rate and column percentages, according to the type of variable. Student's $t$-test was used to compare continuous variables between the groups (Mann-Whitney $U$ test was used for non-normally distributed variables) and the $\chi^{2}$ test and Fisher's exact test were used for categorical variables. $P$-values $<0.05$ were considered statistically significant.

\section{Results}

During the study period, 200 neonates with meningitis were identified among 407 referred infants. There were 126 male infants and 74 female infants. There were 167 non-prenatal infections and 33 prenatal infections. The mean birth weight was $3253 \pm 485 \mathrm{~g}$. There were $11(5.5 \%)$ neonates with low birth weight $(<2500 \mathrm{~g})$ and $9(4.5 \%)$ with high birth weight ( $>4000 \mathrm{~g})$. The mean age at onset of meningitis was $12.1 \pm 8.6$ days. The average duration of hospital stay was $21.0 \pm 7.3$ days (range: 4-43 days). There were 33 (16.5\%) cases identified as EOM and 167 (83.5\%) as LOM. The overall prenatal infection rate was $16.5 \%$ (33 of 200 patients) including 19 cases of maternal fever greater than $38^{\circ} \mathrm{C}, 11$ cases of prolonged rupture of membranes over $18 \mathrm{~h}$, and vaginal colonization with group B Streptococcus was noted in 3 cases. In the investigation of the final outcome of patients, it was observed that the mortality rate was $5.5 \%$. The mortality among infants in 2 cases was due to failure to control the worsening of the disease, and in 9 cases treatment was stopped by their families. There were no other infections during the treatment. However, 10 cases were complicated with polyelectrolyte disorder and another 10 cases were complicated with lung dysfunction.

Ceftriaxone is active against most bacteria causing neonatal sepsis and meningitis including some resistant to first line therapy. However, ESBL (extended spectrum $\beta$-lactamase) mediated resistance to third-generation cephalosporin has appeared among neonatal pathogens. Complications due to ventriculitis, hydrocephalus, convulsions, and relapse were reported in 64/200 (32\%) of infants.

The clinical manifestation of meningitis was highly variable. Some infants presented with nonspecific signs of sepsis, while other infants exhibited signs associated with the central nervous system (CNS), such as irritability, lethargy or seizures. The commonest presenting symptoms in meningitis were fever in 153 (76.5\%), problems with feeding in $70(35 \%)$, lethargy or seizures in $40(20 \%)$ and jaundice in 39 (19.5\%). Other clinical manifestations were apnea, hypoglycemia, hypo- 
Table II. Distribution of bacterial pathogens detected in blood culture in early-onset meningitis (EOM) and lateonset meningitis (LOM)

\begin{tabular}{|c|c|c|c|}
\hline Pathogenic bacteria EOM $(n=8)$ & $N$ & Pathogenic bacteria LOM $(n=41)$ & $N$ \\
\hline Gram-positive bacilli $(n=4)$ : & & Gram-positive bacilli $(n=18)$ : & \\
\hline Staphylococcus haemolyticus & 1 & Staphylococcus haemolyticus & 4 \\
\hline Staphylococcus epidermidis & 1 & Staphylococcus epidermidis & 3 \\
\hline Streptococcus agalactiae & 1 & Staphylococcus aureus & 2 \\
\hline \multirow[t]{6}{*}{ Listeria monocytogenes } & 1 & Enterococcus faecium & 2 \\
\hline & & Streptococcus agalactiae & 2 \\
\hline & & Staphylococcus saprophyticus & 2 \\
\hline & & Pediococcus pentosaceus & 1 \\
\hline & & Staphylococcus hominis & 1 \\
\hline & & Bacillus subtilis & 1 \\
\hline \multicolumn{2}{|l|}{ Gram-negative bacilli $(n=4)$ : } & \multicolumn{2}{|l|}{ Gram-negative bacilli $(n=23)$ : } \\
\hline Klebsiella pneumoniae & 3 & Escherichia coli & 12 \\
\hline \multirow[t]{5}{*}{ Escherichia coli } & 1 & Klebsiella pneumoniae & 6 \\
\hline & & Acinetobacter baumannii & 2 \\
\hline & & Stenotrophomonas maltophilia & 1 \\
\hline & & Pseudomonas aeruginosa & 1 \\
\hline & & Serratia marcescens & 1 \\
\hline
\end{tabular}

tonia, cyanosis and respiratory rate $>60$ per min, heart rate $>180$ beats $/ \mathrm{min}$ or $<100$ beats $/ \mathrm{min}$ and axillary temperature $>37.5^{\circ} \mathrm{C}$ or $<35.5^{\circ} \mathrm{C}$. In general, seizures were often the initial manifestation of meningitis.

Peripheral blood leukocytes varied between $3.0 \times 10^{9} / /$ and $40.19 \times 10^{9} / \mathrm{l}$ with a mean of 15.61 $\times 10^{9} / 1$ including 30 cases of leukocytosis and 5 of leukopenia. Neutrophils varied between $10 \%$ and $93 \%$ with a mean of $49.85 \%$. There were 105 cases with a C-reaction protein (CRP) level over $8 \mathrm{mg} / \mathrm{l}$ and 97 cases with procalcitonin (PCT) over $0.5 \mathrm{ng} / \mathrm{ml}$.

Positive cultures of blood were obtained in 49 (24.5\%) cases, with 28 (57.1\%) cases of Gramnegative bacilli infections. Escherichia coli (13/49), Klebsiella pneumoniae (9/49) and Staphylococcus haemolyticus (5/49) were the commonest pathogenic bacteria. Other organisms were Staphylococcus epidermidis (4/49), Streptococcus agalactiae (3/49), Staphylococcus aureus (2/49), Acinetobacter baumannii (2/49), and Enterococcus faecium (2/49) (Table II).

Cerebrospinal fluid cell count varied between 0 and $9680 \times 10^{6} / \mathrm{l}$ with a median of $76 \times 10^{6} / \mathrm{l}$, including 93 cases with the number of cells more than $100 \times 10^{6} /$. Cerebrospinal fluid protein con- centration varied between 148 and $6670 \mathrm{mg} / \mathrm{l}$, with a median of $1265 \mathrm{mg} / \mathrm{l}$. Mean CSF glucose level was $2.08 \pm 0.96 \mathrm{mmol} / \mathrm{l}$, CSF glucose level varied between 0.1 and $5.96 \mathrm{mmol} / \mathrm{l}$, and there were 66 cases with CSF glucose $<1.7 \mathrm{mmol} / \mathrm{l}$.

\section{Glasgow Outcome Scale and neurological complications}

According to the criteria of the GOS, patients were divided into two outcome groups: good (155 cases, $77.5 \%$, GOS $=5$ ) or unfavorable (45 cases, $22.5 \%$, GOS $=1-4$ ) when we analyzed the effect of the duration of treatment in term infants on prognosis. Twenty-nine infants (64.4\%) had moderate disability and other neurologic complications evidenced by cranial sonography or magnetic resonance imaging/computed tomography (CT) scan in unfavorable outcome patients including $6(13.3 \%)$ cases of hydrocephalus, $3(6.7 \%)$ of encephalomalacia, 3 (6.7\%) of ependymitis, 2 (4.5\%) of subdural effusion and 2 (4.5\%) of mortality. There was higher frequency of poor outcome for patients with prenatal infection. Thus we separated the patients with prenatal infections from those without prenatal infections when analyzing the effects of other factors on prognosis. 
Table III. Influence of duration of antibiotic treatment on prognosis

\begin{tabular}{|c|c|c|c|c|}
\hline $\begin{array}{l}\text { Duration of antibiotic } \\
\text { treatment [days] }\end{array}$ & $\begin{array}{l}\text { Good outcome } \\
\quad(n=155)\end{array}$ & $\begin{array}{l}\text { Poor outcome } \\
\qquad(n=45)\end{array}$ & $\chi^{2}$ value & $P$-value \\
\hline $4-10$ & 10 & 14 & \multirow{2}{*}{20.083} & \multirow{2}{*}{$<0.001$} \\
\hline $10-43$ & 145 & 31 & & \\
\hline $4-14$ & 39 & 21 & \multirow{2}{*}{7.979} & \multirow{2}{*}{0.009} \\
\hline $14-43$ & 118 & 24 & & \\
\hline $4-16$ & 57 & 25 & \multirow{2}{*}{5.085} & \multirow{2}{*}{0.027} \\
\hline $16-43$ & 98 & 20 & & \\
\hline $4-18$ & 74 & 30 & \multirow{2}{*}{5.004} & \multirow{2}{*}{0.028} \\
\hline $18-43$ & 81 & 15 & & \\
\hline $4-21$ & 104 & 33 & \multirow{2}{*}{0.629} & \multirow{2}{*}{0.471} \\
\hline $21-43$ & 51 & 12 & & \\
\hline
\end{tabular}

Clinical prognosis and duration of antibiotic treatment

The duration of antibiotic treatment ranged from 4 to 43 days, and the mean therapy time was $19.74 \pm 7.32$ days. Table III presents the relationship between prognosis and duration of 10, 14, 16, 18 and 21 days, respectively. We found that longer than 21 days of third-generation cephalosporin therapy had no impact on clinical prognosis $(p>0.05)$. Table IV presents the outcomes of our study. We found that shorter hospital stay was associated with unfavorable outcome in 33 prenatal infection infants. The CSF white blood cell and CSF protein and CSF glucose were predictors of unfavorable outcome in 167 non-prenatal infection infants. High CSF cell count increase was associated with unfavorable outcome in 33 prenatal infection infants (Tables III and IV).

\section{Discussion}

Optimal duration of empiric antimicrobial therapy decreases the development of antimicrobial resistance, prevents unwanted changes in flora found in the Neonatal Intensive Care Unit (NICU), and minimizes unnecessary expenses for infants who have negative blood cultures [24]. Prolonged duration of initial empirical antibiotic therapy is associated with an increased risk of necrotizing enterocolitis and death in extremely low birth weight infants [25]. Other adverse effects of prolonged empirical antibiotic therapy include increased risk of neonatal candidiasis and alteration of gut microflora [26-28]. Maintenance of intravenous access for a long period in neonates is difficult and is a burden in many developing countries. Hence, it seems prudent to restrict the duration of empirical antibiotic ther- apy when blood or CSF cultures are sterile and the neonate is asymptomatic.

These survey data have clinical relevance for the hospital, local health authority as well as for the regional health bureau to implement appropriate meningitis surveillance against this invasive bacterial disease. Clinical and demographic characteristics of study infants segregated into initial empirical antibiotic treatment groups are presented.

The incidence of CSF culture-confirmed meningitis is not high. Nevertheless, there is a strong association between meningitis and sepsis with positive blood cultures [29]. Therefore, many studies report that meningitis is associated with a positive culture from the blood or abnormal cerebrospinal fluid parameters [16, 30-32]. Third generation cephalosporin was first reported for the treatment of neonatal bacterial meningitis in 1985, when four neonates presented no sequelae afterward, and it shows several advantages that make it the first-line treatment of meningitis in most developed and developing countries [33-36]. Ceftriaxone is active against most bacteria causing neonatal sepsis and meningitis including some resistant to first line therapy, and synergistic interactions against a variety of micro-organisms have been demonstrated.

The pathogenic microorganism of meningitis cases differs according to the geographic region. The most frequently reported etiology is Gram-positive bacilli such as group B streptococci in the developed countries $[9,10,16]$. In our study, the positive blood culture rate was $24.5 \%$ and the most common bacteria are Gram-negative bacilli such as in early onset meningitis Klebsiella pneumoniae and Escherichia coli in late onset meningitis. The prognosis and outcome in our study were 
Duration of empirical therapy in neonatal bacterial meningitis with third generation cephalosporin: a multicenter retrospective study

Table IV. One factor analysis in prognosis of 200 bacterial meningitis infants

\begin{tabular}{|c|c|c|c|c|c|c|}
\hline \multirow[b]{2}{*}{ Factor } & \multicolumn{3}{|c|}{ Non-prenatal infection $(n=167)$} & \multicolumn{3}{|c|}{ Prenatal infection $(n=33)$} \\
\hline & $\begin{array}{l}\text { Good outcome } \\
(n=137)\end{array}$ & $\begin{array}{l}\text { Poor outcome } \\
\quad(n=30)\end{array}$ & $P$-value & $\begin{array}{c}\text { Good outcome } \\
(n=18)\end{array}$ & $\begin{array}{l}\text { Poor outcome } \\
\quad(n=15)\end{array}$ & $P$-value \\
\hline Sex, male & $81(59.12 \%)$ & $23(76.67 \%)$ & 0.0726 & $11(61.11 \%)$ & $23(73.33 \%)$ & 0.4583 \\
\hline Birth weight $<2500 \mathrm{~g}$ & $9(6.57 \%)$ & $1(3.3 \%)$ & 0.6922 & $1(5.57 \%)$ & $0(0.00 \%)$ & 1.0000 \\
\hline Age at onset [days] & $13.03 \pm 8.84$ & $12.20 \pm 8.14$ & 0.6354 & $10.11 \pm 6.15$ & $9.60 \pm 8.13$ & 0.8393 \\
\hline Hospital stay [days] & $21.11 \pm 7.11$ & $20.46 \pm 8.23$ & 0.3617 & $21.88 \pm 5.92$ & $16.22 \pm 7.22$ & 0.0212 \\
\hline $\mathrm{PROM}>18 \mathrm{~h}$ & $4(2.92 \%)$ & $5(10.00 \%)$ & 0.1105 & $18(100.00 \%)$ & $15(100.00 \%)$ & \\
\hline \multicolumn{7}{|l|}{ Delivery way: } \\
\hline Natural delivery & $89(64.96 \%)$ & $19(63.33 \%)$ & 0.5265 & $8(44.44 \%)$ & $8(53.33 \%)$ & 0.6109 \\
\hline Delivery acouche & $4(2.92 \%)$ & $2(6.67 \%)$ & & $0(0.00 \%)$ & $0(0.00 \%)$ & \\
\hline Cesarean & $44(32.12 \%)$ & $9(30.00 \%)$ & & $10(55.56 \%)$ & $7(46.67 \%)$ & \\
\hline Antibiotic treatment & $0(0.00 \%)$ & $0(0.00 \%)$ & & $4(22.22 \%)$ & $8(53.33 \%)$ & 0.0643 \\
\hline \multicolumn{7}{|l|}{ Clinical symptoms: } \\
\hline Fever & $108(78.83 \%)$ & $20(66.67 \%)$ & 0.1537 & $13(72.22 \%)$ & $12(80.00 \%)$ & 0.6037 \\
\hline Apnea & $4(2.92 \%)$ & $2(6.67 \%)$ & 0.2939 & $3(16.67 \%)$ & $0(0.00 \%)$ & 0.2330 \\
\hline Poor feeding & $25(18.25 \%)$ & $7(23.33 \%)$ & 0.5215 & $3(16.67 \%)$ & $3(20.00 \%)$ & 0.8047 \\
\hline Jaundice & $26(18.98 \%)$ & $5(16.67 \%)$ & 0.2011 & $3(16.67 \%)$ & $5(33.33 \%)$ & 0.4184 \\
\hline Seizures & $26(18.98 \%)$ & $9(30.00 \%)$ & 0.1791 & $2(11.11 \%)$ & $3(20.00 \%)$ & 0.4782 \\
\hline \multicolumn{7}{|l|}{ Abnormal neuroimaging: } \\
\hline Cranial sonography & $32(58.19 \%)$ & $11(55.00 \%)$ & 0.8054 & $2(40.00 \%)$ & $0(0.00 \%)$ & 0.1515 \\
\hline $\mathrm{MRI} / \mathrm{CT}$ & $60(67.42 \%)$ & $18(72.00 \%)$ & 0.6631 & $8(57.14 \%)$ & $4(57.14 \%)$ & 1.0000 \\
\hline \multicolumn{7}{|l|}{ Positive cultures of blood: } \\
\hline Gram-negative bacilli & $27(20.00 \%)$ & $9(33.33 \%)$ & 0.1282 & $9(69.23 \%)$ & $4(30.77 \%)$ & 0.2208 \\
\hline \multicolumn{7}{|l|}{ CSF parameters: } \\
\hline WBCs $\left[\times 10^{6} / 1\right]$ & 49.53 & 151.65 & $<0.001$ & 56.45 & 159.34 & $<0.001$ \\
\hline CSF glucose [mmol/l] & $2.18 \pm 0.99$ & $1.78 \pm 0.90$ & 0.0456 & $1.72 \pm 0.73$ & $2.19 \pm 0.79$ & 0.0871 \\
\hline CSF protein [mg/l] & $1419 \pm 745.64$ & $2022 \pm 1508.09$ & 0.0015 & $1726 \pm 890.87$ & $1283 \pm 900.00$ & 0.4047 \\
\hline \multicolumn{7}{|l|}{ Blood parameters: } \\
\hline White blood cells $\left[\times 10^{9} / 1\right]$ & $13.67 \pm 3.09$ & $15.23 \pm 5.98$ & 0.3480 & $13.77 \pm 6.98$ & $16.79 \pm 6.33$ & 0.3211 \\
\hline Neutrophil [\%] & $49.35 \pm 19.89$ & $48.60 \pm 27.67$ & 0.8627 & $58.08 \pm 20.99$ & $48.50 \pm 18.33$ & 0.2111 \\
\hline Lymphocyte [\%] & $35.54 \pm 15.23$ & $38.35 \pm 18.54$ & 0.4553 & $30.58 \pm 9.45$ & $35.16 \pm 12.67$ & 0.5163 \\
\hline Platelets $\left[\times 10^{9} / 1\right]$ & $361 \pm 97.87$ & $432 \pm 120.97$ & 0.1177 & $284.4 \pm 78.33$ & $431.3 \pm 84.33$ & 0.1269 \\
\hline $\begin{array}{l}\text { C-reaction protein } \\
>8 \mathrm{mg} / \mathrm{l}\end{array}$ & 77 (64.17\%) & $9(34.62 \%)$ & 0.0055 & $14(77.78 \%)$ & $5(26.32 \%)$ & 0.0162 \\
\hline $\begin{array}{l}\text { Procalcitonin } \\
>0.5 \mathrm{ng} / \mathrm{ml}\end{array}$ & 73 (62.39\%) & 9 (31.03\%) & 0.0023 & 12 (70.59\%) & $2(18.18 \%)$ & 0.0068 \\
\hline
\end{tabular}

defined by using clinical status or abnormal neuroimaging examination on hospital discharge and the GOS. We found that shorter hospital stay was associated with unfavorable outcome in 33 prenatal infection infants in our study. This indicates that prenatal infected infants may need longer 
treatment. Two retrospective studies showed that high CSF protein and low CSF glucose concentration were important prognostic factors of complications in neonatal meningitis $[37,38]$. Our study was concordant with this result. Additionally, we found the CSF cell count was associated with unfavorable outcome in term infant meningitis. Though a previous study showed that thrombocytopenia was a main factor of the poor prognostic, the platelet counts in the unfavorable outcome group were not reduced in our study. We advocate rigorous application of ongoing empirical antibiotic treatment and prompt discontinuation of therapy if blood cultures are negative and clinical laboratory measurements indicate a low risk of sepsis. Clinical trials where ceftriaxone has been evaluated in neonates are few. A limitation of this study is the inability to take into account all factors that indicate the severity of illness, although we sought to compare different antibiotic combinations from trials to observe the optimal duration of empirical antibiotic therapy. Additionally, limitations of neonates who developed early sepsis limited the utility of early leukocyte indices and acute phase reactants in identifying culture-negative infants who might benefit from a prolonged duration of antibiotics.

Our study indicated that longer than 21 days of treatment with third generation cephalosporin has no impact on clinical prognosis in term neonates with bacterial meningitis in the negative cerebrospinal fluid culture, and in whom the clinical condition is stable.

In conclusion, we concluded that longer than 3 weeks' administration of third generation cephalosporin has no impact on the infant's prognosis. Because the NICU is kind of sanctuary form antimicrobial stewardship, though many antibodies are used in the NICU, which is the beginning point of this retrospective study. Owing to increasing resistance and the very limited arsenal of new agents, especially against Gram-negative pathogens, carefully designed antibiotic regimens are obligatory for the particular patient neonates. Also it is recommended to minimize antibiotic use and its contingent collateral damage.

\section{Conflict of interest}

The authors declare no conflict of interest.

\section{References}

1. Furyk JS, Swann O, Molyneux E. Systematic review: neonatal meningitis in the developing world. Trop Med Int Health 2011; 16: 672-9.

2. Gaschignard J, Levy C, Romain O, et al. Neonatal bacterial meningitis: 444 cases in 7 years. Pediatr Infect Dis J 2011; 30: 212-7.

3. Okike IO, Ribeiro S, Ramsay ME, Heath PT, Sharland M, Ladhani SN. Trends in bacterial, mycobacterial, and fungal meningitis in England and Wales 2004-11: an observational study. Lancet Infect Dis 2014; 14: 301-7.

4. Okike IO, Johnson AP, Henderson KL, et al. Incidence, etiology, and outcome of bacterial meningitis in infants aged < 90 days in the United Kingdom and Republic of Ireland: prospective, enhanced, national population-based surveillance. Clin Infect Dis 2014; 59: e150-7.

5. Dong Y, Speer CP. Late-onset neonatal sepsis: recent developments. Arch Dis Child Fetal Neonatal Ed 2015; 100: F257-63.

6. Thigpen MC, Whitney CG, Messonnier NE, et al. Bacterial meningitis in the United States, 1998-2007. N Engl J Med 2011; 364: 2016-25.

7. Sivanandan S, Soraisham AS, Swarnam K. Choice and duration of antimicrobial therapy for neonatal sepsis and meningitis. Int J Pediatr 2011; 2011: 712150.

8. Tzialla C, Borghesi A, Perotti GF, Garofoli F, Manzoni P, Stronati $M$. Use and misuse of antibiotics in the neonatal intensive care unit. J Matern Fetal Neonatal Med 2012; 25 Suppl 4: 35-7.

9. Huang FK, Chen HL, Yang PH, Lin HC. Bird's eye view of a neonatologist: clinical approach to emergency neonatal infection. Pediatr Neonatol 2016; 57: 167-73.

10. Zea-Vera A, Ochoa TJ. Challenges in the diagnosis and management of neonatal sepsis. J Trop Pediatr 2015; 61: $1-13$.

11. Martin E, Koup JR, Paravicini U, Stoeckel K. Pharmacokinetics of ceftriaxone in neonates and infants with meningitis. J Pediatr 1984; 105: 475-81.

12. Sullins AK, Abdel-Rahman SM. Pharmacokinetics of antibacterial agents in the CSF of children and adolescents. Paediatr Drugs 2013; 15: 93-117.

13. Pacifici GM. Pharmacokinetics of cephalosporins in the neonate: a review. Clinics (Sao Paulo) 2011; 66: 1267-74.

14. Radetsky M. Duration of treatment in bacterial meningitis: a historical inquiry. Pediatr Infect Dis J 1990; 9: 2-9.

15. Riordan A. Preventing meningitis and septicaemia: are we nearly there yet? Lancet Infect Dis 2014; 14: 363-4.

16. Molyneux E, Nizami SQ, Saha S, et al. 5 versus 10 days of treatment with ceftriaxone for bacterial meningitis in children: a double-blind randomised equivalence study. Lancet 2011; 377: 1837-45.

17. Duke T, Michael A, Mokela D, Wal T, Reeder J. Chloramphenicol or ceftriaxone, or both, as treatment for meningitis in developing countries? Arch Dis Child 2003; 88: 536-9.

18. Sudarsanam TD, Rupali P, Tharyan P, Abraham OC, Thomas K. Pre-admission antibiotics for suspected cases of meningococcal disease. Cochrane Database Syst Rev 2013; 8: CD005437.

19. Heath PT, Nik Yusoff NK, Baker CJ. Neonatal meningitis. Arch Dis Child Fetal Neonatal Ed 2003; 88: F173-8.

20. Cohen-Wolkowiez M, Moran C, Benjamin DK, et al. Early and late onset sepsis in late preterm infants. Pediatr Infect Dis J 2009; 28: 1052-6.

21. Manan MM, Ibrahim NA, Aziz NA, Zulkifly $\mathrm{HH}, \mathrm{Al}-$ Worafi YM, Long CM. Empirical use of antibiotic therapy in the prevention of early onset sepsis in neonates: a pilot study. Arch Med Sci 2016; 12: 603-13.

22. Vergnano S, Sharland M, Kazembe P, Mwansambo C, Heath PT. Neonatal sepsis: an international perspective. Arch Dis Child Fetal Neonatal Ed 2005; 90: F220-4.

23. Koster-Rasmussen R, Korshin A, Meyer CN. Antibiotic treatment delay and outcome in acute bacterial meningitis. J Infect 2008; 57: 449-54. 
24. Shlaes DM, Gerding DN, John JF Jr, et al. Society for Healthcare Epidemiology of America and Infectious Diseases Society of America Joint Committee on the Prevention of Antimicrobial Resistance: guidelines for the prevention of antimicrobial resistance in hospitals. Clin Infect Dis 1997; 25: 584-99.

25. Cotten CM, Taylor S, Stoll B, et al. Prolonged duration of initial empirical antibiotic treatment is associated with increased rates of necrotizing enterocolitis and death for extremely low birth weight infants. Pediatrics 2009; 123: 58-66.

26. Kuppala VS, Meinzen-Derr J, Morrow AL, Schibler KR. Prolonged initial empirical antibiotic treatment is associated with adverse outcomes in premature infants. J Pediatr 2011; 159: 720-5.

27. Afjeh SA, Sabzehei MK, Fahimzad SA, Shiva F, Shamshiri AR, Esmaili F. Antibiotic therapy for very low birth weigh newborns in NICU. Iran J Pediatr 2016; 26: e2612.

28. Mathur NB, Kharod P, Kumar S. Evaluation of duration of antibiotic therapy in neonatal bacterial meningitis: a randomized controlled trial. J Trop Pediatr 2015; 61: 119-25.

29. Bentlin MR, Ferreira GL, Rugolo LM, Silva GH, Mondelli AL, Rugolo A Jr. Neonatal meningitis according to the microbiological diagnosis: a decade of experience in a tertiary center. Arq Neuropsiquiatr 2010; 68: 882-7.

30. Garges HP, Moody MA, Cotten CM, et al. Neonatal meningitis: what is the correlation among cerebrospinal fluid cultures, blood cultures, and cerebrospinal fluid parameters? Pediatrics 2006; 117: 1094-100.

31. Rajesh NT, Dutta S, Prasad R, Narang A. Effect of delay in analysis on neonatal cerebrospinal fluid parameters. Arch Dis Child Fetal Neonatal Ed 2010; 95: F25-9.

32. Gowin E, Wysocki J, Avonts D, et al. Usefulness of inflammatory biomarkers in discriminating between bacterial and aseptic meningitis in hospitalized children from a population with low vaccination coverage. Arch Med Sci 2016; 12: 408-14.

33. Lin TY, Chrane DF, Nelson JD, McCracken GH Jr. Seven days of ceftriaxone therapy is as effective as ten days' treatment for bacterial meningitis. JAMA 1985; 253: 3559-63.

34. Singhi P, Kaushal M, Singhi S, Ray P. Seven days vs. 10 days ceftriaxone therapy in bacterial meningitis. J Trop Pediatr 2002; 48: 273-9.

35. Karageorgopoulos DE, Valkimadi PE, Kapaskelis A, Rafailidis PI, Falagas ME. Short versus long duration of antibiotic therapy for bacterial meningitis: a meta-analysis of randomised controlled trials in children. Arch Dis Child 2009; 94: 607-14.

36. Tunkel AR, Hartman BJ, Kaplan SL, et al. Practice guidelines for the management of bacterial meningitis. Clin Infect Dis 2004; 39: 1267-84.

37. Klinger, G, Chin CN, Beyene J, Perlman M. Predicting the outcome of neonatal bacterial meningitis. Pediatrics 2000; 106: 477-82.

38. Anderson SG, Gilbert GL. Neonatal gram negative meningitis: a 10-year review, with reference to outcome and relapse of infection. J Paediatr Child Health 1990; 26: 212-6. 